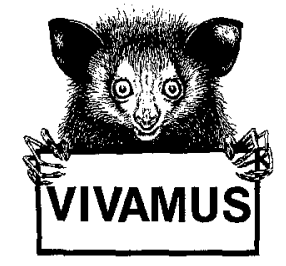

\title{
Experimental Field Studies of Asian Ape Social Systems
}

\author{
John C. Mitani ${ }^{1,2}$ \\ Received July 6, 1988; revised February 9, 1989
}

The Asian apes, orangutans and gibbons, possess unusual social systems among anthropoid primates. Social groups of gibbons consist of mated adult pairs and their offspring; mature orangutans are primarily solitary. Recent experimental field research has begun to yield insights into the behavioral mechanisms employed by these animals to maintain their characteristic patterns of social dispersion. While spatial separation between female orangutans appears to be maintained passively, aggression, which is manifest during direct encounters and long-distance vocal interactions, mediates male asociality. Male-male aggression is the result of intense intrasexual competition occurring between animals for mating access to females. To reduce intrasexual competition, male orangutans have adopted alternative mating tactics. In contrast to female orangutans, female gibbons show marked agonistic tendencies toward conspecifics. Female territoriality contributes to preventing males from becoming polygynous. Male gibbons, restricted to monogamous relationships, attempt to ensure their paternity through intrasexual aggression. These observations suggest that the spatial dispersion of females constrains male mating options in both species. However, variations between orangutan and gibbon social systems can be understood as consequences of the temporal dispersion of sexually receptive females. The temporal clumping of females, due to relatively high operational sex ratios, limits the ability of male gibbons to acquire multiple mates. Conversely, an extremely low operational sex ratio in orangutans creates a strong selection pressure for

'The Rockefeller University Field Research Center, Tyrrel Road, Millbrook, New York 12545. ${ }^{2}$ Present address: Department of Anthropology, University of Michigan, Ann Arbor, Michigan 48109. 
intrasexual competition and polygamous mating. These considerations provide a novel framework for interpreting the social systems of the African apes.

KEY WORDS: orangutans; gibbons; spacing; mating.

\section{INTRODUCTION}

The order primates is notable for the diversity of social systems displayed by different species. This diversity is especially apparent among our closest living relatives, the apes. Here social systems range in complexity from large, open unit-groups of chimpanzees and bonobos to mated pairs of gibbons and solitary orangutans (Tuttle, 1986). Attempting to account for the evolutionary origin and maintenance of this behavioral diversity is an appealing biological problem. For the past several years, I have conducted a program of field research investigating various aspects of the social systems of orangutans and gibbons. One goal of this research has been to evaluate the behavioral mechanisms used by individuals to maintain spacing and mating systems, which are two major components of animal societies.

While previous discussions have focused on ecological factors hypothesized to favor the evolution of ape social systems (Wrangham, 1979; van Schaik and van Hooff, 1983; Rodman, 1984), less attention has been paid to the actual behaviors used by these animals to mediate their characteristic patterns of social dispersion. Nevertheless, the structure of animal societies is a consequence of natural selection operating directly on the behavior of individuals, and a growing body of theory and empirical research suggests that an understanding of social systems depends on behavioral analyses that specify the relationships between animals (Rubenstein and Wrangham, 1986). These analyses stress the importance of examining the behavior of males and females separately.

Because of their greater investment in each zygote, females are a limiting resource for male reproduction in most species (Trivers, 1972). An inevitable result of this asymmetry in parental investment is that males and females differ in their reproductive behavior. While females will tend to act in ways that facilitate the conversion of environmental energy into offspring, male behavior will be characterized by attempts to achieve multiple matings. If female behavior ultimately constrains male mating options, variations in animal societies can be understood in terms of the interaction between female social dispersion and male mating tactics (Bradbury and Vehrencamp, 1977; Emlen and Oring, 1977; Wrangham, 1980). Consequently, recent analyses of animal social systems have begun with descriptions of female social relationships, and then have proceeded by examining how males interact with each other and with females. 
The preceding theoretical framework has provided a useful guide for my field research on Asian ape social systems. However, the wide-ranging habits and dispersed nature of orangutans and gibbons have made it difficult to collect the observations of interactions between animals required to provide adequate accounts of behavioral relationships. I attempted to overcome this empirical problem by employing traditional ethological methods (Tinbergen, 1951). Specifically, I combined field observations with an experimental sound playback technique to simulate interactions between animals. These simulations permit gathering behavioral observations under controlled conditions and, as a result, insights are gained that would be impossible to acquire through a purely naturalistic means.

In this paper, I present a selective review of my field studies of orangutan and gibbon social systems (Mitani, 1984, 1985a-c, 1987). First, the spacing and mating systems of orangutans are described. Here special attention is paid to interactions between males and the manner in which these affect mating behavior. I proceed with a discussion of gibbon territoriality and monogamy, including analyses of behavioral interactions between groups, between females, and between males. A comparison of orangutan and gibbon social systems follows. By identifying relevant behavioral and demographic variables affecting female social dispersion and male mating options, an attempt is made to provide a framework for interpreting the social systems of orangutans and gibbons. I conclude by offering some suggestions for future research.

\section{METHODS}

\section{Study Sites and Subjects}

My field studies of orangutans took place at Mentoko camp in the Kutai Reserve on the east coast of Kalimantan (Indonesian Borneo). Observations spanned 19 months from July 1981 to January 1983 . Field research on two species of gibbons was conducted at the Mentoko study site and at the Cabang Panti research station in the Gunung Palung Nature Reserve, West Kalimantan, Indonesia. Observations of Bornean gibbons (Hylobates muelleri) were conducted from September 1980 to October 1982 at Mentoko camp, while agile gibbons (Hylobates agilis) were the subjects of field work during August through September 1984, July through October 1985, and July through October 1986 . The $3 \mathrm{~km}^{2}$ Mentoko study area comprised mixed, lowland, dipterocarp forest. The larger $15 \mathrm{~km}^{2}$ Cabang Panti station extends over a mixture of lowland dipterocarp, peat swamp, and hill dipterocarp forests. 
Both sites were covered by extensive trail systems marked at $50 \mathrm{~m}$ intervals to facilitate observations, determinations of locations, and experiments.

During the study period, orangutans in the Kutai Reserve lived at a density of approximately 4 animals per $\mathrm{km}^{2}$. The study population consisted of individually recognizable resident and nonresident animals. Individuals encountered on a regular and repeated basis formed the resident population and included one adult male, three adult females with their offspring, and two subadult males. Six adult males, one adult female, and two subadult males were observed irregularly or for brief periods and formed a nonresident population. An undetermined number of unrecognized subadult males were followed occasionally and constituted a part of the nonresident population.

Monogamous family groups formed the study populations of gibbons. Detailed observations of Bornean gibbons at Mentoko camp were limited to two habituated groups. One group included a mated pair and female infant. The second group occupied an adjacent territory and consisted of an adult female, an adult male, a subadult female, a juvenile male, and an infant male. Observations of agile gibbons at Cabang Panti were derived from a more extensive population of nine social groups. These groups averaged 4.6 individuals (range 3-7) and, like Bornean gibbons, comprised mated pairs with their offspring.

\section{Observational Methods}

\section{Orangutans}

The data reported here are based on over $3900 \mathrm{hr}$ of observations of orangutans. Most observations were of animals followed from the time they rose in the morning until the time they went to sleep. Wide-ranging, solitary orangutans are notoriously difficult to find on a consistent basis (Schaller, 1961; Yoshiba, 1964; MacKinnon, 1971). Therefore, once an animal was located, it was followed continuously from dawn to dusk. With the aid of two field assistants, it was possible to follow individual animals over periods lasting as long as 1 month. Following episodes were terminated when we switched observations to another orangutan or to gibbons. The slow and deliberate movements of orangutans facilitated recording aspects of their behavior. Transition times of an individual's activity were recorded to the nearest minute. Activity states included traveling, resting, feeding, mating, and vocalizing.

\section{Gibbons}

Systematic observations of one group of gibbons were conducted from October 1980 to September 1981 at the Mentoko study site. This group was 
followed for 5 continuous days during the first week of each month. The activities of the adult pair were monitored during scan samples conducted at 5-min intervals throughout the daily cycle (Altmann, 1974). Observations of the second group at Mentoko and the nine mated pairs at Cabang Panti were conducted ad libitum. Observation time on all groups totaled over $3000 \mathrm{hr}$.

\section{Experimental Methods}

Experimental methods have been outlined in detail elsewhere (Mitani, $1984,1985 b, c, 1987)$. Briefly, test subjects were located and followed for a variable time before each playback presentation. Following this control period, the playback signal was broadcast and the behavior of animals was monitored. By comparing the activities of orangutans and gibbons during the periods before playbacks to their activities during and following playbacks, it was possible to determine any short-term changes in their behavior as a function of signal presentation.

Control signals of heterospecific sounds were typically presented to test subjects (Mitani, 1985c, 1987). Comparisons between control and experimental playbacks consistently revealed that the playback protocol and apparatus did not affect the responses of animals. Since the time of day and activity of the animals were expected to influence responsiveness, playbacks were conducted during restricted times and during periods when the test subjects were stationary. Further precautions were taken to prevent orangutans and gibbons from identifying the source of the playback and habituating to the artificial stimuli. Animals were exposed to playbacks infrequently, and were never permitted to see the recording equipment during trials.

Approach and vocal responses proved to be useful in evaluating changes in behavior due to playback presentation. Orientation and approach toward the speaker, alarm calls, and, in the case of gibbons, singing responses, were reliably elicited from animals during most trials. In addition, the latency to approach the playback site was employed successfully as a measure of responsiveness.

\section{RESULTS AND DISCUSSION}

\section{Orangutans}

\section{Background}

Previous field research revealed that orangutans are essentially solitary creatures and, in this respect, unique among diurnal anthropoid primates 
(Rodman, 1973; MacKinnon, 1974; Horr, 1975; Rijksen, 1978; Galdikas, 1979, 1985a). The only enduring social unit consists of a mother and her offspring. Females occupy small, overlapping home ranges varying between 0.4 and $6 \mathrm{~km}^{2}$; these ranges are found within the larger ranges of males.

Despite numerous long-term studies of orangutans in the wild, it has proven difficult to document the behavioral factors contributing to their asocial existence. The inactive lifestyle of orangutans, coupled with their movements over large areas, led to few sightings of animals during initial field research (Schaller, 1961; Yoshiba, 1964). Subsequent field work reported interactions between males rarely; only seven observations of encounters between adult male Bornean orangutans were recorded after 8 years of field research (Rodman, 1973; MacKinnon, 1974; Horr, 1975; Galdikas, 1979). Based on these limited observations, it was hypothesized that the social dispersion of males was mediated by intense male-male agonistic behavior, for which detailed accounts are rare.

While a lack of data hindered understanding of male-male relationships, behavioral interactions between the sexes were equally difficult to document. Long life spans, long interbirth intervals, wide-ranging habits, and the solitary nature of orangutans combined to limit observations of mating behavior. Rodman (1973) and Horr (1975) were the first to propose a general model of orangutan sexual behavior. These researchers hypothesized that high-ranking adult males father most infants after passing through a developmental stage as small subadults, during which their reproductive success is limited. Recent observations in Sumatra do not contradict this model of the orangutan mating system (Schurmann and van Hooff, 1986); however, support is weak since it has not been possible to determine the paternity of many infants (see below).

While the Rodman-Horr model was developed largely on the basis of theoretical considerations and only a small number of observations of mating, additional field research recorded mating behavior in greater detail. Nevertheless, before the aforementioned study of Sumatran orangutans (Schurmann and van Hooff, 1986), mating between wild animals was still observed infrequently, and the paucity of data led to a curious situation in which authors presented different accounts of orangutan sexual behavior using the same observations. For example, MacKinnon (1974) did not witness mating by adult males, and initially argued that these animals were postreproductive; he later amended this proposal without offering further data (MacKinnon, 1979). In contrast, Galdikas (1979) originally suggested that subadult males are effectively eliminated from reproduction; she subsequently proposed that subadults reproduce occasionally, but did not provide additional observations (Galdikas, 1985b). It was obvious that easy answers regarding the nature of the orangutan mating system would not arise given a limited data base. 
Taking advantage of an unusual situation during which three resident females in adjacent ranges conceived over a short period, I was able to observe several instances of mating by orangutans (Mitani, 1985a). In addition, the use of experimental playbacks of male calls, combined with observations of direct interactions between animals, has begun to yield insights into the complexities of the orangutan mating and spacing systems (Mitani, 1985a, b; Rodman and Mitani, 1987).

\section{Spacing System}

Behavioral observations have indicated that interactions between females are neither particularly affiliative nor agonistic (Rijksen, 1978; Galdikas, 1984). Relationships between individual females appear to be stable, but adult animals never associate for more than a few days (Galdikas, 1984). In contrast, encounters between males are marked by severe aggression. Thus, all interactions between adult males observed at Mentoko were aggressive, involving fights, chases, and other agonistic behaviors (Mitani, 1985a; Fig. 1). Adult males were typically more tolerant of subadult males, while subadults were rarely agonistic toward one another (Fig. 1). While these data indicate that the solitary nature of adult males is enforced during direct behavioral interactions as suggested by previous research, additional field observations and experiments indicate that the characteristic spatial dispersion of orangutans is regulated vocally over long distances (Galdikas, 1983; Mitani, 1985b).

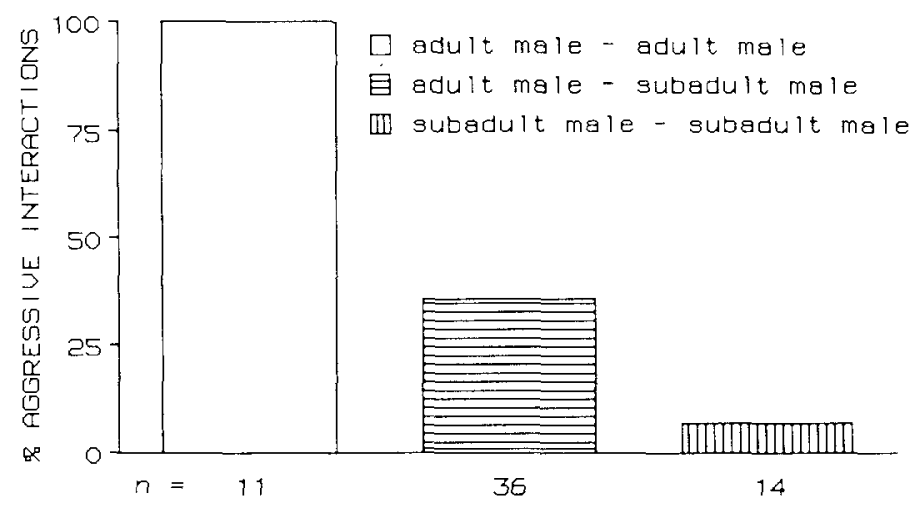

Fig. 1. The percentage of interactions between male orangutans involving aggressive behavior. Aggressive behavior was scored if a fight, chase, or attempted chase between animals took place. The figure is redrawn and reprinted with permission from Mitani (1985a). 

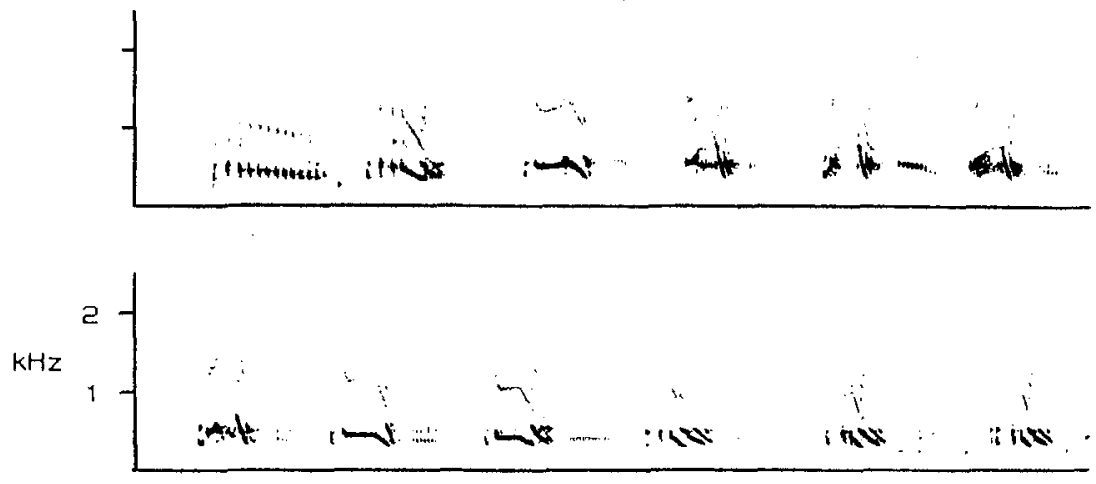

5 seconds

Fig. 2. Spectrograms of an adult male orangutan long call. The 30 -sec segment illustrates the three stages of the call. Introductory "bubbling" sounds are depicted by the first element. Broad-band "roars" are illustrated by elements 4-7. The last three elements form part of the concluding stage. The spectrogram was produced on a Princeton Applied Research FFT real time spectrum analyzer. Analysis range: $0-2048 \mathrm{~Hz}$, frequency resolution of $4 \mathrm{~Hz}$.

Adult male orangutans emit a sex-specific loud vocalization, termed the "long call" (MacKinnon, 1971). It can be heard by a human observer on the ground up to $800 \mathrm{~m}$ away and consists of three distinct stages. Figure 2 shows a representative spectrogram of a section of a long call. The call usually lasts from 1-3 min, beginning with a set of low-frequency, low-amplitude "bubbling" sounds. These grade into a series of higher amplitude, broad-band "roars." The call concludes with another set of low-amplitude, low-frequency elements.

Examination of the vocal repertoires of other forest-dwelling primate species typically reveals the presence of a loud call, usually given by adult males (review in Snowdon, 1986). The analogy is frequently drawn between primate loud calls and male oscine bird song; the assertion is often made that these calls play a role in regulating spacing. Nevertheless, few field data exist to evaluate this proposal. To test this hypothesis directly in the field, a series of playback experiments, using tape-recorded long calls, was conducted (Mitani, 1985b). While experimental results were consistent with the proposed spacing function of long calls, they did so in an entirely nonobvious manner (Fig. 3). There is an approach-avoidance system based on dominance relationships, whereby low-ranking adult and small subadult males avoid calls and high-ranking adult males approach the calls of others, presumably to displace them (cf. Galdikas, 1983).

Males have not been observed to herd solitary female orangutans (Mita$\mathrm{ni}, 1985 \mathrm{a}$ ), and females are usually separated from other conspecifics by several hundred meters. These factors appear to create a situation in which females 


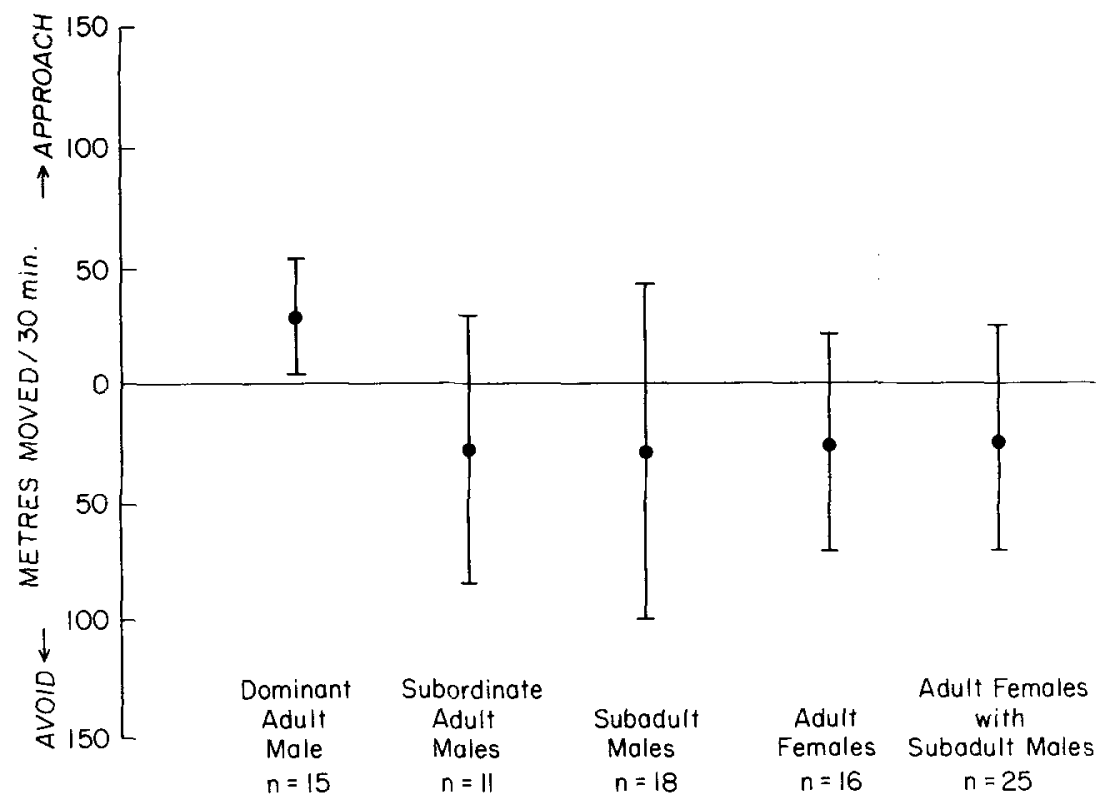

Fig. 3. Net change in distance of orangutans to the playback site following long call presentations. Distances were computed by subtracting the test subjects' average distance to the playback speaker during the $30 \mathrm{~min}$ following playback from their average distance to the speaker during the 30 min prior to playback. Means \pm SD are shown. Rank relationships between males were determined during behavioral interactions using approach-avoidance criteria (Mitani, 1985b). The figure is reprinted with permission from Mitani (1985b).

may choose mates selectively; several field workers have argued that females show a preference for high-ranking adult males (Rodman, 1973; Rijksen, 1978; Galdikas, 1979; Schurmann and van Hooff, 1986). These authors supply anecdotal observations of animals moving in the general direction of long calls to suggest that females use these vocalizations to locate high-ranking males over long distances. However, encounters and subsequent mating between animals following these movements have not been recorded. Despite the absence of definitive observations on this issue, the proposed intersexual function of long calls continues to gain widespread support (Tuttle, 1986; Dunbar, 1987). Nevertheless, the only direct test of the mate attraction hypothesis failed to support it (Mitani, 1985b). Experimental playbacks in the field did not reveal any tendency by sexually active females to move toward the long call of a high-ranking male (Fig. 3).

\section{Mating System}

The theory of sexual selection proposes that intrasexual competition affects the mating success of individuals (Darwin, 1871). Since the availabil- 


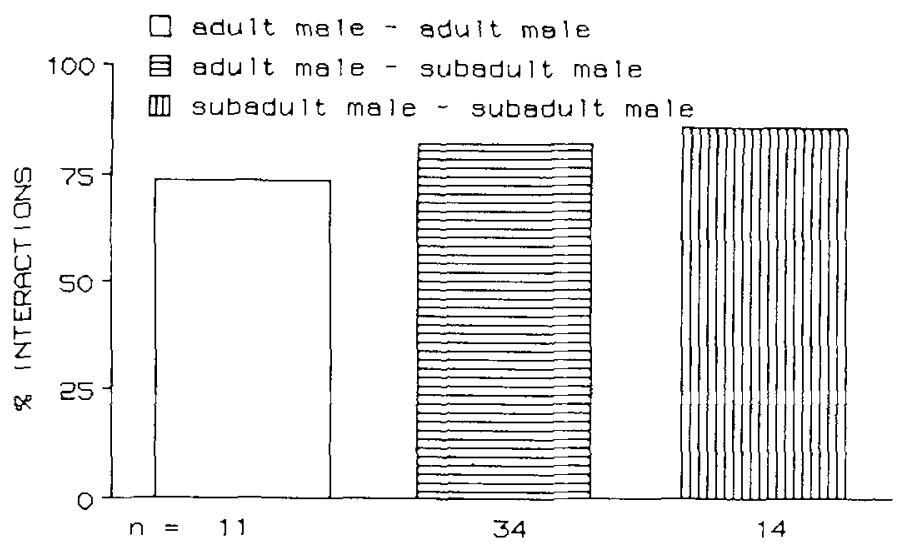

Fig. 4. The percentage of interactions between male orangutans in which females were present.

ity of mates limits male reproduction, male-male competition for mating access to females typically results (Trivers, 1972). The intensity of male-male competition depends on the relative difference in parental investment between the sexes and the number of breeding females to breeding males in the population - the operational sex ratio (Emlen and Oring, 1977). Sexual selection theory predicts intense male-male competition when female parental investment greatly exceeds that of males and when the operational sex ratio is male-biased. Among orangutans, prolonged periods of gestation and lactation force females to invest much more in offspring than males. In addition, the long interbirth intervals of female orangutans, which can last up to 8 years (Galdikas, 1982), create heavily male-biased operational sex ratios.

Viewed within the framework, the spatial dispersion of male orangutans, resulting from aggressive encounters and long-distance vocal interactions, is a manifestation of the intense competition taking place among males for mating access to females. Most interactions observed at Mentoko between males occurred in the presence of females (Fig. 4), and in many of these encounters, males disrupted mating relationships between conspecific pairs (Mitani, 1985a). During 5 of 8 interactions involving adults, the highest ranking adult male displaced another male that had mated with a female. Similarly, larger adult males terminated associations between subadult males and females on 13 occasions during which mating took place. In all 12 encounters involving subadult males, one animal avoided the other, which enabled the other animal to start or to continue mating with a female.

Intrasexual competition has led males of different age classes to adopt alternative mating tactics (Mitani, 1985a; Table I). Previous observations suggested that small subadult males, unable to compete directly with larger adult males, mate with females during brief associations only (MacKinnon, 1974; Galdikas, 1979, 1985b). However, it is unclear from these reports 
Table I. Frequencies of Mating and Durations of Mating Associations as a Function of Male Age

\begin{tabular}{lccccc} 
& & \multicolumn{3}{c}{$\begin{array}{c}\text { Durations of mating } \\
\text { associations (days) }\end{array}$} \\
\cline { 3 - 6 } & Forced matings & Unforced matings & $X \pm \mathrm{SD}$ & Median & $N$ \\
\hline Subadult male & 144 & 7 & $8 \pm 9$ & 6.7 & 11 \\
Adult male & 13 & 15 & $2 \pm 2$ & 1.9 & 7 \\
\hline
\end{tabular}

whether interactions were always observed from start to finish. Interactions observed in their entirety at Mentoko revealed that subadult males maintain prolonged mating associations during which they frequently force females to copulate (Table I). This pattern differed from that shown by adult males, for whom forced and unforced copulations occurred with equal frequency during shorter associations (Table I). Although mating frequencies during associations did not differ between males of the two age-classes, subadults achieved more matings by persistently maintaining contact with sexually active females. In all associations observed in their entirety, subadults continued to follow females until displaced by a larger male. Subadults also showed a characteristic pattern of initiating associations; they mated with resistant females within a few minutes after contact on each occasion.

The reproductive success of males adopting different mating tactics remains to be documented. Few data exist to support the common assertion that adult male orangutans are more successful reproductively than subadult males (Rodman, 1973; Horr, 1975; Rijksen, 1978; Galdikas, 1979; Schurmann and van Hooff, 1986). The paternity of only one infant has been determined reliably in the field. Schurmann ascertained that a high-ranking adult male fathered one infant born during his study (Schurmann and van Hooff, 1986). In contrast, the highest ranking male at the Mentoko site was not the probable father of one infant born during my study, since he did not associate with the mother during the month of conception (Mitani, 1985a). Additional observations are needed to determine whether the reproductive success of adults exceeds that of subadults, whether frequent mating by subadults results in more offspring than adults, or whether the different mating tactics of animals are maintained in equilibrium, with males of different ages fathering an equal number of offspring.

\section{Gibbons}

\section{Background}

The asocial, promiscuous spacing and mating patterns displayed by orangutans contrast sharply with that shown by gibbons. Previous studies, 
beginning with the pioneering field work of C.R. Carpenter (1940), revealed that gibbons possess unusual social systems among anthropoid primates (Leighton, 1987). With the possible exception of the concolor gibbon, $\mathrm{Hylo}$ bates concolor (Haimoff et al., 1986), social groups consist of a mated pair of adults and their offspring. Offspring mature within their natal groups and disperse at 8-10 years. In this way, group sizes between 2 and 7 individuals are maintained. These social groups maintain site-specific, exclusive territories averaging $30-40$ ha.

Until recently, methodological problems have precluded detailed investigations of the behavioral mechanisms maintaining territoriality and monogamy in gibbons. Such study requires observations of interactions between mated pairs and neighboring conspecific groups, and observations of mated pairs interacting with solitary, floating individuals. Unfortunately, such interactions are rarely observed in nature. For example, only seven intergroup encounters were witnessed in over $1500 \mathrm{hr}$ of observation of one group of Bornean gibbons (Mitani, 1985c). When interactions occur, events take place rapidly and high in the canopy, making it difficult to record behavioral events in detail. To circumvent these methodological problems, I simulated interactions through the use of sound playback. The singing behavior of gibbons permits this possibility.

Male gibbons engage in prolonged singing performances, during which they emit different types of species-typical song (Fig. 5). Performances usually begin in the hour before dawn and last an average of $45 \mathrm{~min}$. Songs are sung discontinuously, with short bursts of song followed by intervals of silence several times the length of the song itself. The songs of male agile gibbons, two extreme examples of which are shown in Fig. 5, average approximately $3 \mathrm{sec}$. While some performances begin spontaneously in the absence of overt cues, many performances are elicited by the singing of a neighboring male. Contersinging between males typically takes place, and affects performances in predictable ways (Mitani, 1988).

Singing behavior is not limited to males. Mated females also engage in elaborate singing performances. They are joined by their mates during most performances, thus creating duets. In the Bornean gibbon, females begin performances with a series of simple tonal frequency upsweeps (Fig. 5). After 1-2 min of singing in this manner, males join their mates by uttering sounds of varying acoustic morphology (Fig. 5). Females and males coordinate their singing efforts in this fashion for another 1-2 min period, at the end of which the male ceases to sing, while the female emits her "great call." In the Bornean gibbon, the female great call consists of a rapid series of frequency upsweeps that decrease in duration (Fig. 5). After the first great call, females and males sing together for another variable period, at the end of which the female delivers another great call. This pattern is repeated several times over a period lasting an average of $15 \mathrm{~min}$ (Mitani, 1985c). 

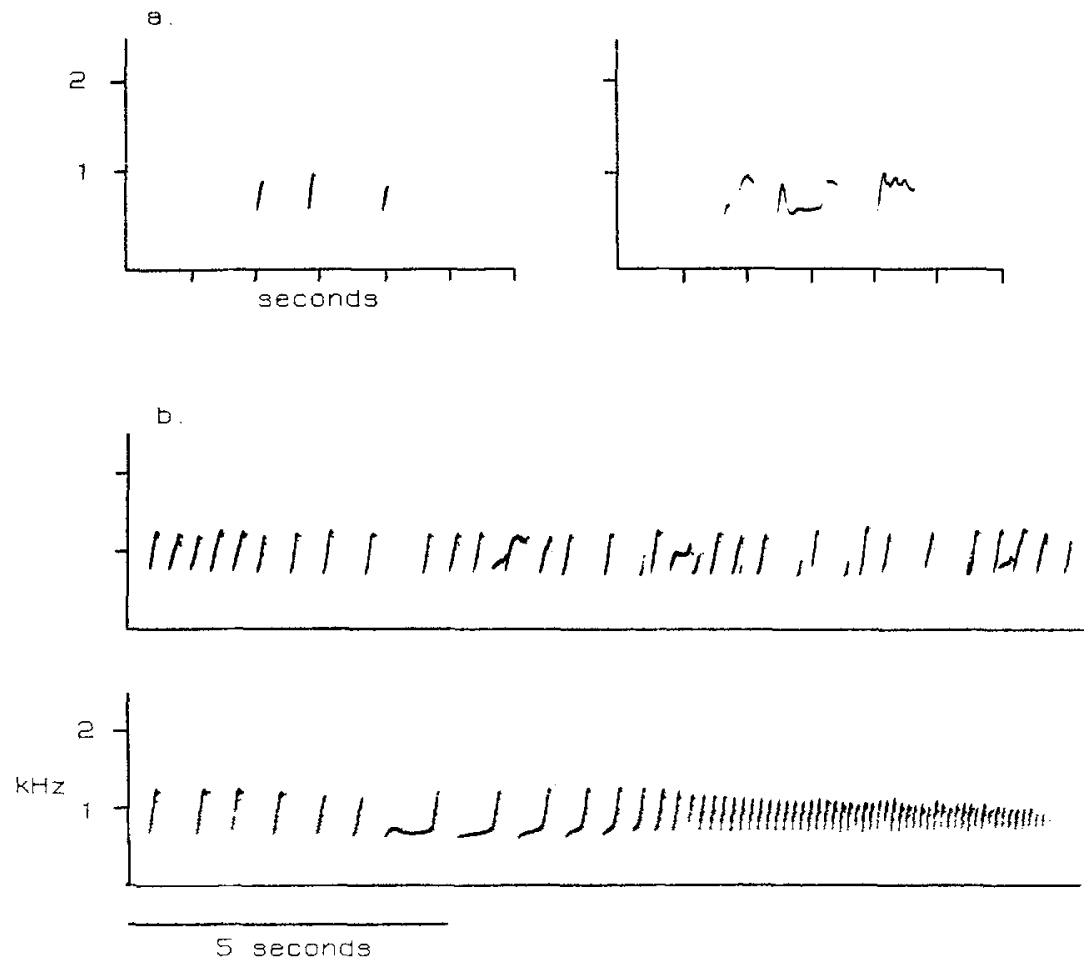

Fig. 5. (a) Spectrograms of male agile gibbon (Hylobates agilis) songs. (b) Spectrogram of a section of a Bornean gibbon (Hylobates muelleri) song duet. The upper panel displays elements sung by the female and male, while the lower panel shows the female great call. See text for further explanation and Fig. 2 for details of spectrogram production.

\section{Territoriality}

Two behavioral mechanisms are employed by animals to maintain territoriality (Waser and Wiley, 1979). It may result from animals varying their agonistic tendencies as a function of location. For example, tendencies to approach and supplant conspecifics at the center of the territory but not at boundaries typically generate exclusive ranges. Alternatively, site fidelity, associated with the defense of a specified individual distance, could maintain territorial spacing patterns (e.g., Marler, 1956). The exclusive use of space would result if animals restricted their activities to limited areas and if they consistently displaced conspecifics which approached within the normal individual distance.

To investigate the behaviors used by gibbons to maintain their territorial spacing system, mated pairs of Bornean gibbons were presented-conspecific 

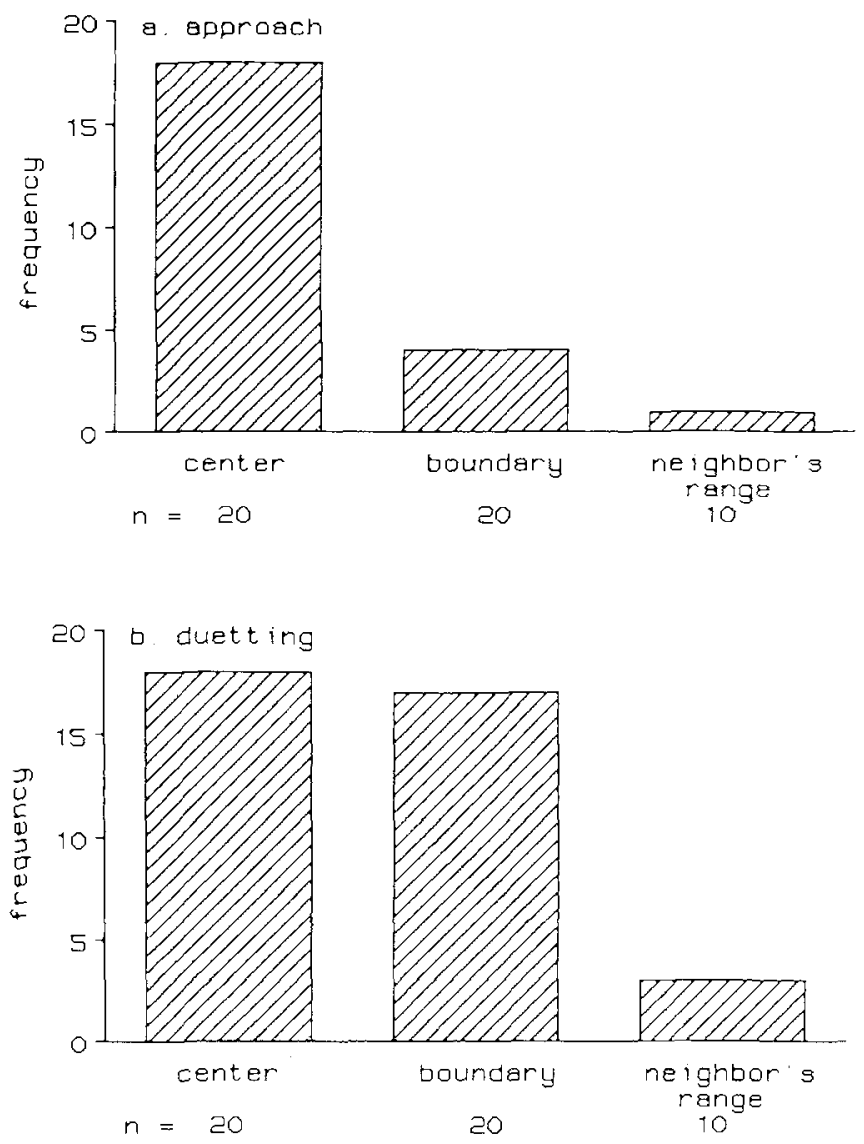

Fig. 6. Responses of Bornean gibbons to song duet playbacks presented from different locations. The number of trials resulting in a positive response are shown. (a) Approach responses; (b) duetting responses.

groups as simulated by song duet playbacks (Mitani, 1985c; Fig. 6). Responses to playbacks showed a clear tendency by animals to approach simulated conspecifics when they unambiguously intruded at territorial center positions. The tendency to approach waned at peripheral locations, and essentially vanished at locations outside a test group's territory. These data indicate that gibbons vary their agonistic tendencies as a function of territorial location and, in so doing, generate a pattern of exclusive ranges. The qualitatively different responses to playbacks administered from different locations, but from standard distances, show that gibbon territoriality is not behaviorally mediated by a fixed response to the proximity of conspecifics.

A closer examination of response measures indicates that females play an important role in maintaining territoriality. In addition to leading group 
movements to confront simulated intruders, females initiated apparently aggressive duets in response to song duet playbacks (Fig. 6b). Thus, female gibbons differ from female orangutans by exhibiting marked agonistic tendencies toward conspecifics. Female aggression appears to play a critical role in the maintenance of gibbon monogamy (see below).

\section{Interspecific Variation in Territorial Behavior}

To investigate the generality of the results obtained with Bornean gibbons, the preceding experiments were replicated using a population of agile gibbons as test subjects (Mitani, 1987). An interesting difference that emerged from these experiments is that female agile gibbons did not take as active a role in range defense as female Bornean gibbons. Clear and unambiguous territorial intrusions by neighboring pairs, simulated with song duets, typically resulted in mated female Bornean gibbons leading group approaches toward the playback site (Fig. 7a). In similar playback trials, female agile gibbons led group approaches infrequently (Fig. 7b). Additional field experiments and observations revealed that the pattern of male-dominated territorial defense shown by agile gibbons is also characteristic of lar gibbons (Raemaekers and Raemaekers, 1985). In contrast, mated female Kloss's gibbons play a leading role in territorial behavior similar to Bornean gibbon females (Tenaza, 1975).

Two factors may account for the interspecific sex differences shown in experiments. First, the observed interspecific variability in responsiveness may have been due to variable costs of territorial behavior for females and males. In the majority of cases, where mated male agile gibbons led group approaches toward intruders, their mates carried small infants. In these situations, the costs associated with lactation and infant care may have constrained the behavior of females and limited their ability to take a more active role in territorial defense. Alternatively, differences between the two studies may reflect limitations in sampling. Experiments using Bornean gibbons as subjects involved repeated exposures of song to two groups. In contrast, I sampled the responses of eight groups in experiments with agile gibbons. Thus, the pattern of female responsiveness shown by Bornean gibbons may have been biased due to the small number of animals tested. This sampling limitation plagues nearly all primate field studies. Given the long-lived nature of subjects, studies of primates under natural conditions have failed to sample the behavior of more than a few individuals or groups at any given time (Smuts et al., 1987). As a result, the generality of findings is often questionable. Recognizing this problem, which is inherent in previous field studies, I recently attempted to expand the study population of agile gibbons. Observations have been extended to include 28 groups (Mitani, unpublished data). 

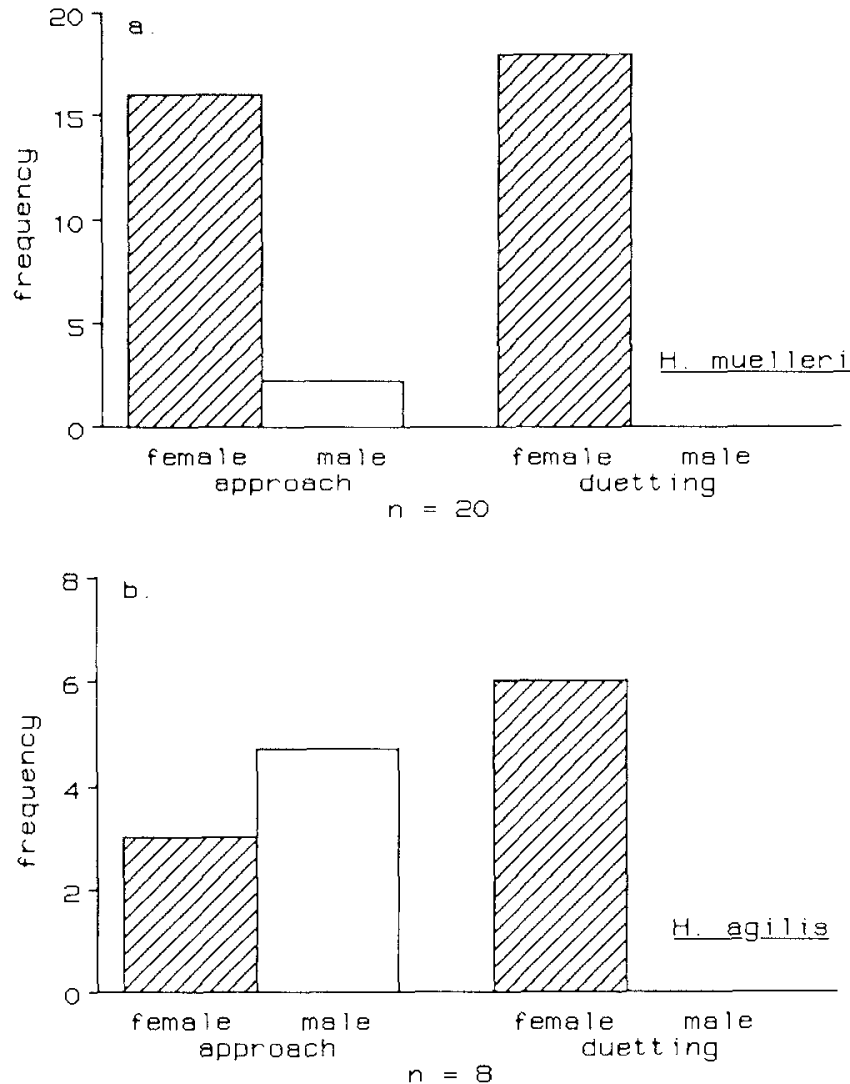

Fig. 7. Responses of gibbons to song duet playbacks presented from positions within the center of the test subjects' territories. The number of trials eliciting approach and duetting responses are shown. The individual of the mated pair which initiated the response is scored. (a) Responses of Bornean gibbons (H. muelleri); (b) responses of agile gibbons (H. agilis).

\section{Monogamy}

Since the availability of mates generally limits male reproductive success and monogamy restricts mating opportunites, male gibbons should be under strong selective pressure to oppose monogamous relationships. Theoretical and empirical interest in gibbon monogamy is due to its existence in the presence of such counterselection. 
The apparent paradox posed by monogamy in gibbons is heightened by the fact that male gibbons, unlike many other monogamous males, do not contribute a substantial amount of nonshareable parental care (Wittenberger and Tilson, 1980). Among the nine species of gibbons, only siamang males exhibit a measureable amount of parental care in the form of infant carrying (Chivers, 1974). Parental care is frequently cited as an important factor leading to the evolution of monogamy. For example, one common explanation for the widespread occurrence of monogamy in birds is that nestlings require the parental effort of two individuals (Lack, 1968).

What then precludes male gibbons from acquiring multiple mates? Several investigators have suggested that the solution to this puzzle lies in the behavior of mated females (Tenaza, 1975; Brockelman and Srikosamatara, 1984; Mitani, 1984, 1987; Raemaekers and Raemaekers, 1985). Specifically, intrasexual aggression among females has been hypothesized to inhibit the formation of social groups, thereby preventing males from monopolizing more than one female. To investigate this hypothesis experimentally, a series of playbacks with Bornean gibbons was conducted in which female singing behavior was used to simulate encounters between established mated pairs and solitary females (Mitani, 1984). Figure 8 presents experimental support for the female aggression hypothesis by showing that, when confronted with a solitary female, mated females initiated aggressive duetting responses and led group approaches toward the playback site, presumably to evict the phantom intruder.

If male gibbons are restricted to monogamous relationships, one would expect them to behave in a manner that would ensure their paternity by preventing extra-pair copulations between their mates and other males (Trivers, 1972). To examine this proposal, mated male Bornean gibbons were confronted with solitary floating males, as mimicked through male song playback (Mitani, 1984). The results of these experiments conformed to the prediction; mated males consistently led silent group approaches toward the playback site in search of the intruding male (Fig. 8).

\section{Comparison Between Orangutan and Gibbon Sociat Systems}

The preceding results point to some interesting parallels and contrasts between the spacing and mating systems of orangutans and gibbons. First, both female orangutans and gibbons limit the social options of males by living apart from conspecifics. However, female asociality in each species is mediated by entirely different behaviors. In the case of orangutans, females are neither particularly affiliative nor aggressive toward one another; in con- 

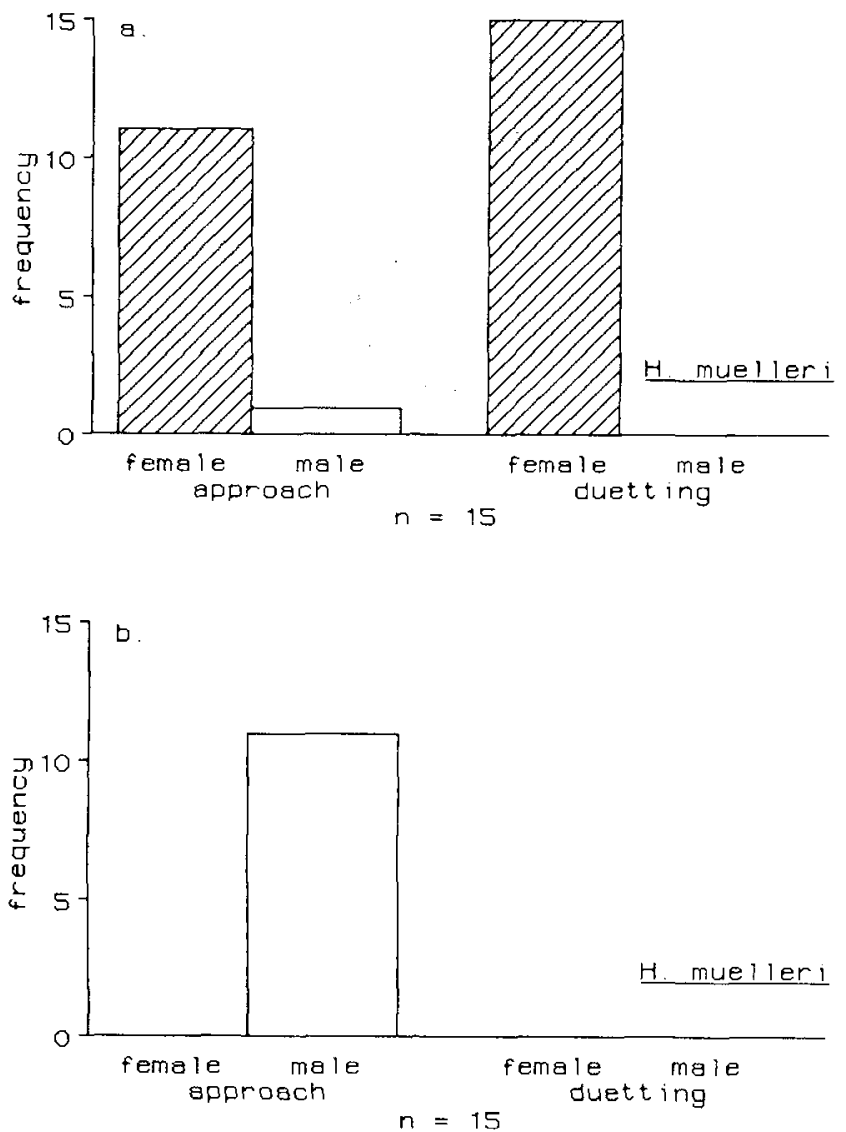

Fig. 8. Responses of Bornean gibbons to female and male song playbacks. The number of trials eliciting approach and duetting responses are shown. The individual of the mated pair which initiated the response is scored. (a) Responses to female songs; (b) responses to male songs.

trast, interactions between female gibbons are marked by severe aggression. These observations, illustrating the maintenance of superficially similar social patterns through diverse behavioral means, underscore the limitations of investigations which categorize primate social systems in gross structural terms (Crook and Gartlan, 1966; Terborgh, 1983; van Schaik and van Hooff, 1983) and highlight the insights gained through examinations of proximate behavioral mechanisms (cf. Rubenstein, 1986; Wrangham, 1986).

Second, despite the asocial nature of female orangutans and gibbons, the males of each species "map" onto them in different manners, producing radically different mating systems. In the case of orangutans, promiscuity 
Table II. Population Densities, Interbirth Intervals, and Operational Sex Ratios of Gibbons and Orangutans ${ }^{a}$

\begin{tabular}{lccccc}
\hline & $\begin{array}{c}\text { Population } \\
\text { density }\end{array}$ & $\begin{array}{c}\text { Breeding } \\
\text { female } \\
\text { density }\end{array}$ & $\begin{array}{c}\text { Breeding } \\
\text { male } \\
\text { density }\end{array}$ & $\begin{array}{c}\text { Interbirth } \\
\text { interval }(y)\end{array}$ & OSR $^{b}$ \\
\hline Gibbon & 12.3 & 4.3 & 4.0 & 3 & 0.35 \\
Orangutan & 4.0 & 1.0 & 1.7 & 5 & 0.12 \\
\hline
\end{tabular}

${ }^{a}$ All densities are expressed as the number of animals per $\mathrm{km}^{2}$. Estimates for gibbons are taken from a population of agile gibbons (Hylobates agilis) at the Cabang Panti research station in the Gunung Palung Nature Reserve ( $n=28$ groups). Breeding female and male densities included counts of reproductively mature animals. Estimates for orangutans are derived from a population at Mentoko camp in the Kutai Reserve ( $n=16$ animals).

${ }^{b}$ OSR $=$ number of breeding females/breeding males/year.

has evolved, in the case of gibbons, monogamy. Here I suggest that demographic variables, through their effects on the operational sex ratio (Emlen and Oring, 1977), determine male mating options. Using the average interbirth interval for females and the mean population densities of each species, it is possible to compute the average number of breeding females that will be available to a male gibbon or orangutan each year (Table II). This number is relatively high for gibbons. A correspondingly low "environmental potential for polygamy" (sensu Emlen and Oring, 1977; Fig. 9) results, since each male cannot monopolize successively available females. Thus, the temporal availability of breeding females interacts with their solitary nature to limit the ability of male gibbons to acquire multiple mates. In contrast, the vanishingly small number of breeding females available to male orangutans creates strong selection for intrasexual competition, a higher environmental potential for polygamy, and a situation in which the mating success of a promiscuous male may exceed that of monogamous males.

Consideration of the interaction between the spatial and temporal dispersion of sexually active females (Fig. 9) appears to provide an answer as to why male gibbons do not defend the ranges of multiple females (Wrangham, 1979, 1987). An additional implication of the preceding analysis is the possibility of dissociating territoriality from monogamy. Typically among primates, monogamy and territoriality co-occur and a causal link between them is hypothesized frequently (Smuts et al., 1987). The model presented here suggests that this co-occurrence holds only insofar as the factors that favor territoriality simultaneously favor operational sex ratios conducive to monogamy. Monogamy may also evolve in the absence of territoriality if conditions independently lead to uniform operational sex ratios.

To summarize, I have suggested that two factors, the spatial and temporal dispersion of females, regulate the patterns of gibbon and orangutan 


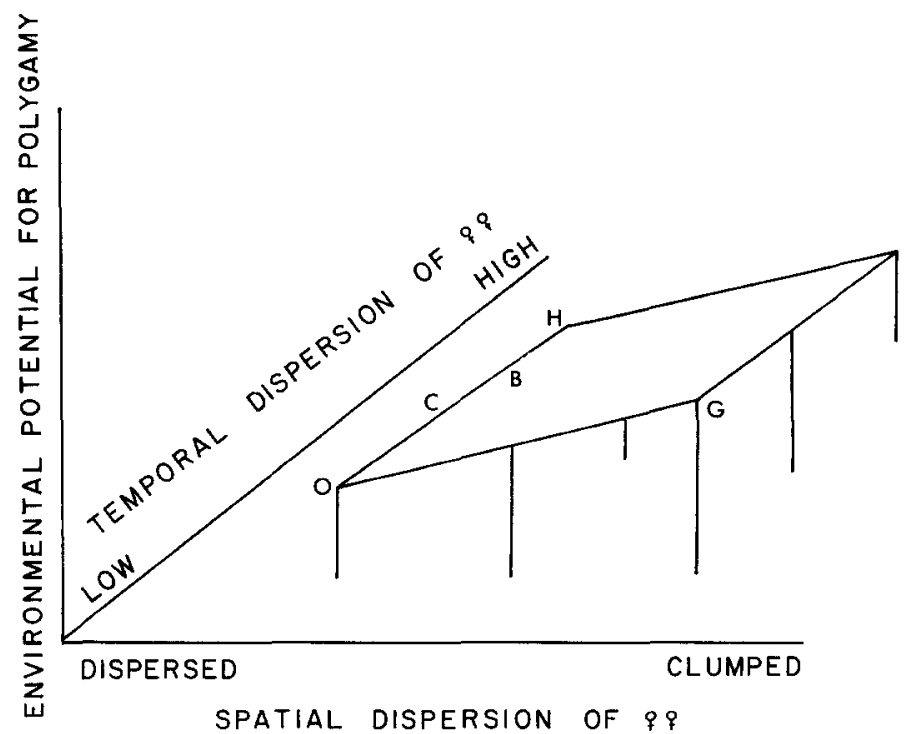

Fig. 9. The "environmental potential for polygamy" (sensu Emlen and Oring, 1977) expressed as a function of the spatio-temporal dispersion of females. Spatial clumping creates opportunities for males to monopolize several females. Conversely, the temporal clumping of females, resulting from relatively high operational sex ratios, limits the ability of males to acquire multiple mates. O, orangutans; $\mathrm{H}$, gibbons; $\mathrm{C}$, chimpanzees; $\mathrm{B}$, bonobos; $\mathrm{G}$, gorillas - see text for further explanation.

mating systems (Fig. 9). While the spatial dispersion of females is often invoked to limit male mating options among gibbons (Tenaza, 1975; Brockelman and Srikosamatara, 1984; Mitani, 1984, 1987; Raemaekers and Raemaekers, 1985), the comparison with orangutans provides a unique perspective and indicates that the solitary nature of females is a necessary but not sufficient condition to account for gibbon monogamy. In addition, the temporal dispersion of females appears to play a critical role in determining Asian ape mating systems. While the degree of breeding synchrony is usually cited as the primary variable affecting the temporal dispersion of females (Emlen and Oring, 1977; Robinson, 1986), here I have attempted to draw attention to the importance of prolonged interbirth intervals as an additional, relevant variable for long-lived organisms.

I conclude this discussion by noting that the preceding observations provide a novel framework for interpreting African ape social systems. An examination of chimpanzee and bonobo social systems illustrates the impact that the temporal dispersion of females has in determining mating patterns (Fig. 9). Female bonobos are frequently found in groups, while female chim- 
panzees are primarily solitary (Nishida and Hiraiwa-Hasegawa, 1987). Given the spatial dispersion fo females, stronger selection for polygyny and associated sexual dimorphism should occur in bonobos relative to chimpanzees. However, this selective force is offset by the temporal dispersion of females. Due to their longer periods of sexual receptivity and shorter interbirth intervals (Nishida and Hiraiwa-Hasegawa, 1987), the temporal availability of bonobo females appears to be greater than that of female chimpanzees. As a result, one would predict a greater degree of polygyny and sexual dimorphism to be manifest by chimpanzees. Few data on bonobo mating patterns exist to evaluate the first proposal; however, the greater degree of sexual dimorphism found in chimpanzees compared to bonobos conforms to the second prediction (Zihlman and Cramer, 1978).

\section{Directions for Future Research}

Although results of these studies have filled some of the gaps in our knowledge of the social systems of the Asian apes, understanding is far from complete. Clear evidence regarding active mate choice by parous female orangutans does not exist, but relevant field data have been difficult to collect (Mitani, 1985a). Additional field work will be required to resolve this matter conclusively. While the issue of female mate choice is still open to question, aspects of male-male competition remain unclear as well. Paternity determinations of more infants are needed to clarify the origin and maintenance of alternative mating tactics employed by male orangutans. Gibbon species have been characterized as behaviorally uniform with respect to their social systems (e.g., Leighton, 1987). Nevertheless, interspecific sex differences in territorial behavior and recent field observations, which suggest polygynous mating (Srikosamatara and Brockelman, 1987), reveal the variability in gibbon spacing and mating systems. Further field experiments and observations are necessary to investigate the causes of this behavioral variability.

The results presented here represent the first attempts at an experimental analysis of ape social systems under field conditions. I suggest that similar analyses hold promise for clarifying some aspects of the social systems of the African apes. For example, elucidating the behavioral relationships of female chimpanzees has been difficult due to their solitary nature (Nishida and Hiraiwa-Hasegawa, 1987). Careful application of the experimental techniques outlined here could serve as a means to simulate interactions and thereby help to determine whether networks of female relationships exist in the wild.

While natural selection operates directly through behavior at a proximate level, social structure is ultimately affected by ecological variables. Pro- 
tection from predators and advantages associated with harvesting food resources are frequently invoked as critical selective pressures shaping ape social systems (Wrangham, 1979, 1986; van Schaik and van Hooff, 1983). Nevertheless, predation and the nature of food resources have seldom been studied directly and, as a result, discussions of the ecological factors affecting ape social systems have produced few compelling conclusions. Empirically sufficient (sensu Lewontin, 1974) tests of hypotheses regarding the selective importance of these ecological variables are clearly needed. Field experiments (cf. Mitani, $1985 \mathrm{c}$, p. 81 ) may provide a means to identify relevant variables; however, critical tests will require field research on predators, instead of the prey, as well as detailed botanical investigations.

\section{ACKNOWLEDGMENTS}

My field work in Indonesia was sponsored by the Indonesian Institute of Sciences, the Indonesian Directorate General of Forest Protection and Nature Conservation, the Indonesian Association of Zoological Parks, and the Indonesian National Biological Institute. Research was funded by grants from the NSF BNS-8022764, the L.S.B. Leakey Foundation, the National Geographic Society, the Wenner-Gren Foundation, the National Academy of Sciences, the University of California, Wildlife Conservation International, and by fellowships from the Regents of the University of California and the NIH NRSA F32 NS07670. Additional funding was supplied by Orville Smith and Peter Rodman thorugh USPHS grants RR00169 and R00166. Current support from the Harry Frank Gugghenheim Foundation and the NSF BNS-8805275 facilitated preparation of the manuscript. I thank Sdr. Yum, Bastar, and Tarmiji for field assistance, Chuck Darsono for unfailing logistic support, Kathy MacKinnon and Peter Rodman for comments on the manuscript, Esther Arruza for preparing the manuscript, and the Darsono family for adopting me and providing an optimal environment in which to write in Indonesia. Finally, I owe a special debt to the late Dana Wheeler; I am deeply grateful for her support and encouragement.

\section{REFERENCES}

Altmann, J. (1974). Observational study of behavior: Sampling methods. Behaviour 49: 227-267. Bradbury, J., and Vehrencamp, S. (1977). Social organization and foraging in emballonurid bats. III. Mating systems. Behav. Ecol. Sociobiol. 2: 1-17.

Brockelman, W., and Srikosamatara, S. (1984). Maintenance and evolution of social structure in gibbons. In Prueschoft, H., Chivers, D., Brockelman, W., and Creel, N. (eds.), The Lesser Apes, Edinburgh University Press, Edinburgh, pp. 298-323. 
Carpenter, C. R. (1940). A field study in Siam of the behavior and social relations of the gibbon (Hylobates lar). Comp. Psychol. Monogr. 16: 1-212.

Chivers, D. (1974). The Siamang in Malaya, Karger, Basel.

Crook, J., and Gartlan, S. (1966). Evolution of primate societies. Nature, Lond. 210: 1200-1203. Darwin, C. (1871). Sexual Selection and the Descent of Man, John Murray, London.

Dunbar, R. (1987). Primate Social Systems, Croom Helm, London.

Emlen, S., and Orign, L. (1977). Ecology, sexual selection and the evolution of mating systems. Science 197: 215-223.

Galdikas, B. (1979). Orangutan adaptation at Tanjung Puting Reserve: Mating and ecology. In Hamburg, D., and McCown, E. (eds.), The Great Apes, Benjamin Cummings, Menlo Park, California, pp. 194-233.

Galdikas, B. (1982). Wild orangutan birth at Tanjung Puting Reserve. Primates 23: 500-510.

Galdikas, B. (1983). The orangutan long call and snag crashing at Tanjung Puting Reserve. Primates 24: 371-384.

Galdikas, B. (1984). Adult female sociality among wild orangutans at Tanjung Puting Reserve. In Small, M. (ed.), Female Primates: Studies by Women Primatologists, Liss, New York, pp. 217-235.

Galdikas, B. (1985a). Orangutan sociality at Tanjung Puting. Am J. Primatol. 9: 101-119.

Galdikas, B. (1985b). Subadult male orangutan socialtiy and reproductive behavior at Tanjung Puting. Am. J. Primatol. 8: 87-99.

Haimoff, E., Yang, X.-J., He, S.-J., and Chen, N. (1986). Census and survey of wild blackcrested gibbons (Hylobates concolor concolor) in Yunnan Province, People's Republic of China. Folia Primatol. 46: 205-214.

Horr, D. A. (1975). The Borneo orangutan: Population structure and dynamics in relationship to ecology and reproductive strategy. In Rosenblum, L. (ed.), Primate Behavior: Developments in Field and Laboratory Research, Vol. 4, Academic Press, New York, pp. 307-323.

Lack, D. (1968). Ecological Adaptations for Breeding in Birds, Metheun, London.

Leighton, D. (1987). Gibbons: Territoriality and monogamy. In Smuts, B., Cheney, D., Seyfarth, R., Wrangham, R., and Struhsaker, T. (eds.), Primate Societies, University of Chicago Press, Chicago, pp. 135-145.

Lewontin, R. (1974). The Genetic Basis of Evolutionary Change, Columbia University Press, New York.

MacKinnon, J. (1971). The orangutan in Sabah today. Oryx 11: 141-191.

MacKinnon, J. (1974). The behaviour and ecology of wild orangutans (Pongo pygmaeus). Anim. Behav. 22: 3-74.

MacKinnon, J. (1979). Reproductive behavior in wild orangutan populations. In Hamburg, D., and McCown, E. (eds.), The Great Apes, Benjamin-Cummings, Menlo Park, California, pp. 256-273.

Marler, P. (1956). Territory and individual distance in the chaffinch Fringilla coelebs. Ibis 98: 496-501.

Mitani, J. (1984). The behavioral regulation of monogamy in gibbons (Hylobates muelleri). Behav. Ecol. Sociobiol. 15: 225-229.

Mitani, J. (1985a). Mating behaviour of male orangutans in the Kutai Game Reserve, Indonesia. Anim. Behav. 33: 392-402.

Mitani, J. (1985b). Sexual selection and adult male orangutan long calls. Anim. Behav. 33: 272-283.

Mitani, J. (1985c). Gibbon song duets and intergroup spacing. Behaviour 92: 59-96.

Mitani, J. (1987). Territoriality and monogamy among agile gibbons (Hylobates agilis). Behav. Ecol. Sociobiol. 20: 265-269.

Mitani, J. (1988). Male gibbon (Hylobates agilis) singing behavior: Natural history, song variations and function. Ethology 79: 177-194.

Nishida, T., and Hiraiwa-Hasegawa, M. (1987). Chimpanzees and bonobos: Cooperative relationships among males. In Smuts, B., Cheney, D., Seyfarth, R., Wrangham, R., and Struhsaker, T. (eds.), Primate Societies, University of Chicago Press, Chicago, pp. 165-177. 
Raemaekers, J., Raemaekers, P. (1985). Field playback of loud calls to gibbons (Hylobates lar): Territorial, sex-specific and species-specific responses. Anim. Behav. 33: 481-493.

Robinson, S. (1986). The evolution of social behavior and mating systems in the blackbirds (Icterinae). In Rubenstein, D., and Wrangham, R. (eds.), Ecological Aspects of Social Evolution, Princeton University Press, Princeton, pp. 175-200.

Rodman, P. (1973). Population composition and adaptive organisation among orangutans of the Kutai Reserve. In Michael, R., and Crook, J. (eds.), Comparative Ecology and Behaviour of Primates, Academic Press, London, pp. 171-209.

Rodman, P. (1984). Foraging and social systems of orangutans and champanzees. In Rodman, P., and Cant, J. (eds.), Adaptations for Forating in Nonhuman Primates, Columbia University Press, New York, pp. 134-160.

Rodman, P., and Mitani, J. (1987). Orangutans: Sexual dimorphism in a solitary species. In Smuts, B., Cheney, D., Seyfarth, R., Wrangham, R., and Struhsaker, T. (eds.), Primate Societies, University of Chicago Press, Chicago, pp. 145-154.

Rubenstein, D. (1986). Ecology and sociality in horses and zebras. In Rubenstein, D., and Wrangham, R. (eds.), Ecological Aspects of Social Evolution, Princeton University Press, Princeton, pp. 282-302.

Rubenstein, D., and Wrangham, R. (1986). Ecological Aspects of Social Evolution, Princeton University Press, Princeton.

Schaller, G. (1961). The orangutan in Sarawak. Zoologica 46: 73-82.

Schurmann, C., and van Hooff, J. (1986). Reproductive strategies of the orangutan: New data and a reconsideration of existing socio-sexual models.Int. J. Primatol. 7:265-287.

Smuts, B., Cheney, D., Seyfarth, R., Wrangham, R., and Struhsaker, T. (1987). Primate Societies, University of Chicago Press, Chicago.

Snowdon, C. (1986). Vocal communication. In Mitchell, G., and Erwin, J. (eds.), Comparative Primate Biology, Vol. 2A, Liss, New York, pp. 495-530.

Srikosamatara, S., and Brockelman, W. (1987). Polygyny in a group of pileated gibbons via a familial route. Int. J. Primatol. 8: 389-393.

Tenaza, R. (1975). Territory and monogamy among Kloss' gibbons (Hylobates klossi) in Siberut Island, Indonesia. Folia Primatol. 24: 60-80.

Terborgh, J. (1983). Five New World Primates, Princeton University Press, Princeton.

Tinbergen, N. (1951). The Study of Instinct, Oxford University Press, Oxford.

Trivers, R. (1972). Parental investment and sexual selection. In Campbell, B. (ed.), Sexual Selection and the Descent of Man, Aldine, Chicago, pp. 136-179.

Tuttle, R. (1986). Apes of the World, Noyes Publications, Park Ridge, New Jersey.

van Schaik, C., and van Hooff, J. (1983). On the ultimate causes of primate social systems. Behaviour 85: 91-117.

Waser, P., and Wiley, R. H. (1979). Mechanisms and evolution of spacing in animals. In Marler, P., and Vandenbergh, J. (eds.), Handbook of Behavioral Neurobiology, Vol. 3, Plenum, New York, pp. 159-223.

Wittenberger, J., and Tilson, R. (1980). The evolution of monogamy: Hypotheses and evidence. Ann. Rev. Ecol. Syst. 11: 197-232.

Wrangham, R. (1979). On the evolution of ape social systems. Soc. Sci. Inf. 18: 335-368.

Wrangham, R. (1980). An ecological model of female-bonded primate groups. Behaviour 75 : 262-300.

Wrangham, R. (1986). Ecology and social relationships in two species of chimpanzees. In Rubenstein, D., and Wrangham, R. (eds.), Ecological Aspects of Social Evolution, Princeton University Press, Princeton, pp. 352-378.

Wrangham, R. (1987). Evolution of social structure. In Smuts, B., Cheney, D., Seyfarth, R., Wrangham, R., and Struhsaker, T. (1987). Primate Societies, University of Chicago Press., Chicago, pp. 282-296.

Yoshiba, K. (1964). Report of the preliminary survey on the orangutan in North Borneo. Primates 5: 11-26.

Zihlman, A., and Cramer, D. (1978). Skeletal differences between pygmy (Pan paniscus) and common chimpanzees (Pan troglodytes). Folia Primatol. 29: 86-94. 